\title{
The Role of Green Productive Community in Healthy Urban Planning
}

\author{
Yuanchuan YANG, School of Architecture in Tianjin University, China \\ Yukun ZHANG, School of Architecture in Tianjin University, China \\ Stephen CAIRNS, ETH Zürich Future Cities Laboratory, Switzerland \\ Si HUANG, School of Architecture in Tianjin University, China \\ Jie ZHENG, School of Architecture in Tianjin University, China
}

\begin{abstract}
Building healthy cities is facing urbanization challenges. The reason lies in the problems of excessive scale and lack of flexibility in the structure and function of the city at present. It is necessary to adopt a distributed network pattern with hierarchical systems and a systematic planning strategy with production functions. First of all, determine the role of community-scale as the basic unit in health care and disaster prevention and mitigation. Secondly, it analyzes the health potential of productive strategies and demonstrates its health security ability in daily relaxation state and abnormal emergency state through the case of urban agricultural practice. Finally, it is proposed to formulate health planning strategies with systematic thinking, and on the basis of using the implantation and reorganization of productive functions to increase the resilience and sustainability of the system, the full integration of productive systems into healthy urban planning is more helpful to give full play to its role.
\end{abstract}

\section{Keywords}

Productive function, Community scale, Healthy city, Resilient planning, Urban agriculture, Systematic thinking

\section{Acknowledgments}

Supported by the Natural Science Foundation of China Project (Number: 51978443); the National Natural Science Foundation of China (Number: 51708395); 2019 Tianjin Graduate Research and Innovation Project (Number: 2019YJSB175)

\section{Introduction}

Since the epidemic of COVID-19 was declared as a Public Health Emergency of International Concern (PHEIC) by the World Health Organization (WHO) on January 30th, 2020, it has rapidly evolved into a global health and economic crisis. Before the outbreak of the epidemic, 2020 was set by the United Nations as the 'super year' of the sustainable development goal (SDG). This pandemic sounded the alarm for global development, especially how healthy urban planning should deal with the risks of health and disasters. In 2019, WHO used the Health Emergency and Disaster Risk Management (Health-EDRM) to 
refer to the broad intersection of health and disaster[1]. Therefore, human health care and urban disaster prevention and mitigation can be studied as a healthy whole.

In history, many major urban public health events have promoted the construction of public environment, promoted landscape fairness and reflected on the relationship between man and nature [2]. The COVID19 epidemic not only caused huge death, injury and economic losses, but also led to the global "isolation" dilemma of sealing the country, cities, districts and even buildings, causing food supply crisis and mental health crisis [3]. It shows once again that the city urgently needs to have the functional layout of 'selfsufficiency and self-healing'. Green productive community is to tap the potential of urban production function represented by urban agriculture as a response strategy.

The research on urban agriculture is mainly focused on production technology, planning paradigm, implementation policy, organizational form and related urban theory [4][5][6][7]. Compared with its important contribution to dealing with climate change and many key challenges in cities (space use, community cohesion, landscape beautification, waste recycling, life function), the planning field mostly affirms the effect of urban agriculture on physical and mental health from the role of landscape spatial elements in environment, behavior and emotion [8], and seldom studies its complex action mechanism on urban health as a green productive function [9]. Thus ignoring the potential of urban agriculture to deal with health planning in peacetime and in a state of emergency.

In recent years, the health potential of urban agriculture has become more apparent as countries around the world have proposed that the focus of planning for the construction of healthy cities (communities) should be interventions in the field of healthy food systems. Examples include the 2014 Canadian Healthy Community Practice Guide [10], the United States 2017 Metrics for Planning Healthy Community [11] and Australia's Health and Well-being Priorities [12]. China released the Healthy China 2030 Plan in 2016. In the next 10 years, there is an urgent need to explore strategies for reform and innovation, fully integrate health into the field of urban planning, and at the same time ensure the sustainability and fairness of development.

\section{Challenges, analysis and methods of healthy urban planning}

\subsection{Health challenge}

Urbanization is one of the major trends in the 21st century, with more than $55 \%$ of the world's population living in urban areas, which is expected to reach $68 \%$ by 2050 [13]. Over the past four decades, rapid urbanization has brought unprecedented health benefits to urban population in China, as well as changes in lifestyle and socio-spatial environment, which is both an opportunity and a challenge to protect and promote the health and well-being of residents. In particular, the scale and frequency of outbreaks of health (disease, injury) and disasters (natural, man-made) are constantly changing [14], while mental health and ageing are eroding the health advantages of cities, controlling economic costs and improving equity also need to be addressed [15].

It is found that the above risk factors involve complex areas and are interrelated, and the health sector alone can't effectively solve the modern challenges facing urban health in China. Both health care and disaster prevention and reduction have the characteristics of timeliness and abruptness, which must be linked with urban changes and formulate strategies for short-term correction and long-term adaptation, that is, the urban health planning of 'combine peacetime with epidemic (disaster, war) time'.

\subsection{Problem analysis}

Cities have taken action to address the above challenges, such as enhancing health prevention and control, promoting universal health coverage, controlling environmental pollution and improving the 
livability of the urban environment. Although substantial progress has been made, there are still problems of inadequate management, space out of control, environmental risks and system fragility in urban planning.

(1) The scale of urban structure is too large and it is urgent to strengthen the meso-micro spatial planning.

At present, cities have the characteristics of large-scale population, high-density buildings, high-frequency interaction and long-span mobility, which aggravate the lack of management, space out of control and the dislocation of the relationship between the two [16]. For example, 1) Too large planning scale leads to functional simplification, unable to form an effective health management unit. 2) Limited management budget and authority, and lack of necessary infrastructure, resulting in insufficient ability of epidemic prevention and disaster prevention. 3) Spatial structure leads to the separation of work and residence, resulting in a large number of mobility overlap, aggregation and interference. 4) The dislocation of planning and governance leads to the lack of relatively independent and supporting configuration needed for management. 5) The imbalance between health facilities and spatial development affects the rights and interests of vulnerable groups. Therefore, it is necessary to organize space with distributed structure and establish a hierarchical system of overall planning and coordination.

(2) The urban system is inflexible and it is an urgent need to transform from consumption to production.

Modernist planning thought is based on the ontology and dualism of the separation of culture and nature, and tends to deny the organic origin of the city [17]. In fact, human beings only reschedule the complex biogeochemical cycle in cities according to their own needs, from the input of resources such as water, air, food, energy and matter to the discharge of heat, inorganic or organic wastes. many of these processes are both natural and urban, covering a wide range of scales from individual to ecology. The view that 'the city is essentially unnatural' makes people ignore the resilience of the urban system itself, and the one-way linear flow consumption system is too dependent on the external environment. Among them, energy-intensive industries are the root cause of many environmental pollution problems, which seriously affect the livability of the urban environment, and these environmental risks aggravate the fragility of the system. Therefore, it is necessary to use productive strategy as a means to restore the elastic system of ecological function.

\subsection{Coping methods}

The hierarchical system of urban planning is reflected in the distributed network pattern, while its elastic system is supported by productive functional system, and the two need to match each other. (figure 1)

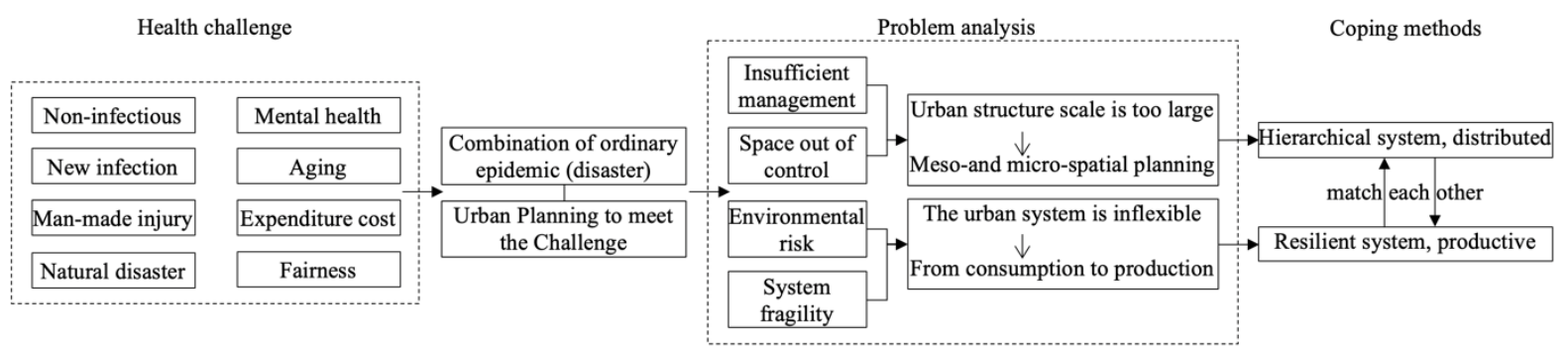

Figure 1. Challenges, Analysis and Methods of Healthy Urban Planning.

(1) Hierarchical system and distributed network

The hierarchical system of 'central-province-city (county)', the management organization of urban health, is reflected in the overall pattern of 'center-periphery' of spatial planning. this mapping relationship exposes two problems: 1) The overall planning and coordination of 'top-down' also needs 'bottom-up' feedback and response. 2) The tree structure is not suitable for meso-and micro-scale spatial organization. 
Therefore, it is necessary to take the distributed semi-network structure as the framework to improve the health hierarchy at the community level.

Distributed network has the characteristics of relative independence and mutual support, which is mainly reflected in: 1) As the basic unit boundary in high-density cities. Usually is the scope of community management, epidemic (disaster) is a protective isolation zone. 2) Give full play to the advantages of selforganization to deal with emergencies. 3) Support the community unit with the function of 'local life, integrated work and living'. Such as Life Circle, Superblock, 20-Minute Neighborhood and other planning concepts. 4) Achieve short-term self-sufficiency of some resources, reserve emergency refuge space and facilities. 5) Balance the interface between human and nature, animals and plants. We should not only be close to the urban green habitat, but also stay away from zoonotic pathogens.

(2) Resilient system and productive strategy

'Resilience' in the field of planning has many similar definitions. Simply and mechanically, resilience is the ability to restore the system to a predetermined equilibrium state, measured by resistance and recovery speed. However, in natural and social systems, in addition to adapting to external disturbances, it is more important to change by modifying internal dynamics and reorganizing structures and processes, thus continuously developing [18]. Therefore, community flexibility can be interpreted as a healthy process that can promote community evolution, and the concept of green productivity is the internal driving force that triggers change.

Productive strategy is a design method based on the concept of productive city [19], which enables cities to 'actively' carry out green production of material, energy and space on the basis of 'passively' reducing resource consumption. Strive to maximize the flexibility and sustainability of the urban system. After activating the production potential, the community elasticity is mainly reflected in two aspects: 1) improving the resilience, stronger resistance to change and faster recovery speed; 2) improving the current state, shorter adaptation time and better daily state. (figure 2)

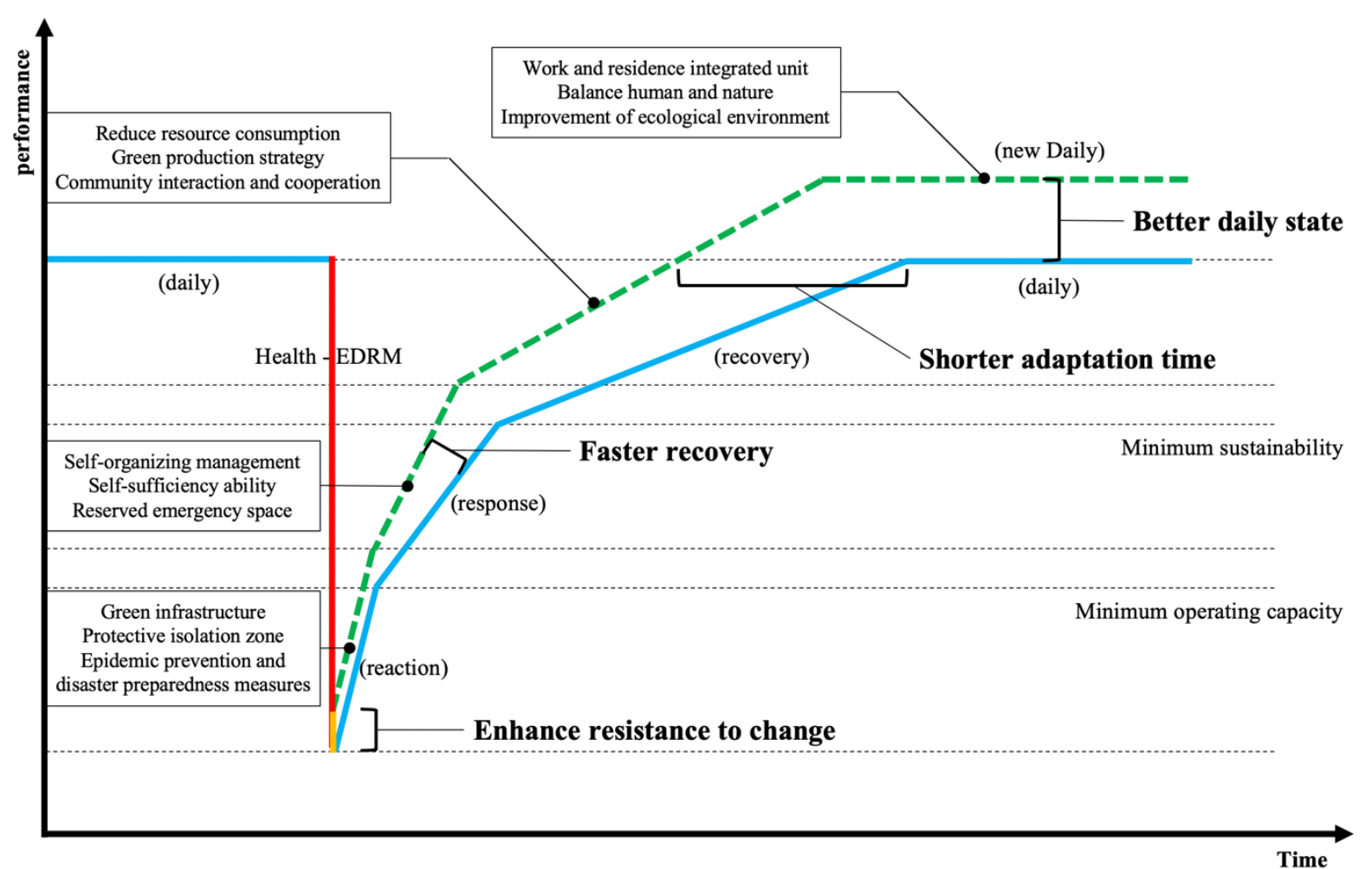

Figure 2. Resilience System Using Distributed Structures and Productive Strategies. 


\section{Health planning potential of community productive strategies}

\subsection{Community planning as a basic unit}

(1) The role of community scale in health care

Planning plays a key role in improving public health and protecting security. The many factors that determine overall health are divided into five main categories-genetic factors, health care, social (cultural, economic) environment, physical environment (architectural, natural) and behavioural patterns [20]. Among them, community planning directly or indirectly affects the latter three factors, such as shaping the urban physical environment, promoting a healthy lifestyle, affecting the social cultural and economic environment, limiting harmful environmental exposure, and helping to change behavior patterns. Moreover, the percentage of social environment, physical environment and behavior patterns is greater than the sum of genetic factors and health care (figure 3 , left). The health impact pyramid (figure 3, right) [21] describes the potential effects of five different types of interventions. The closer to the bottom, the larger the coverage of the population and the less individual effort is required. For example, the 'Fiveyear Health Impact ( $\mathrm{HI}-5)^{\prime}$ [22] proposed by the Centers for Disease Control and Prevention (CDC) for the community has a direct impact on the two-tier interventions at the bottom of the pyramid with the greatest impact-the social determinant of health (SDH), and changing the environment (in order to make individual default choices healthier and easier). Therefore, community planning can have a positive impact on public health at an earlier life cycle with better cost-effectiveness.
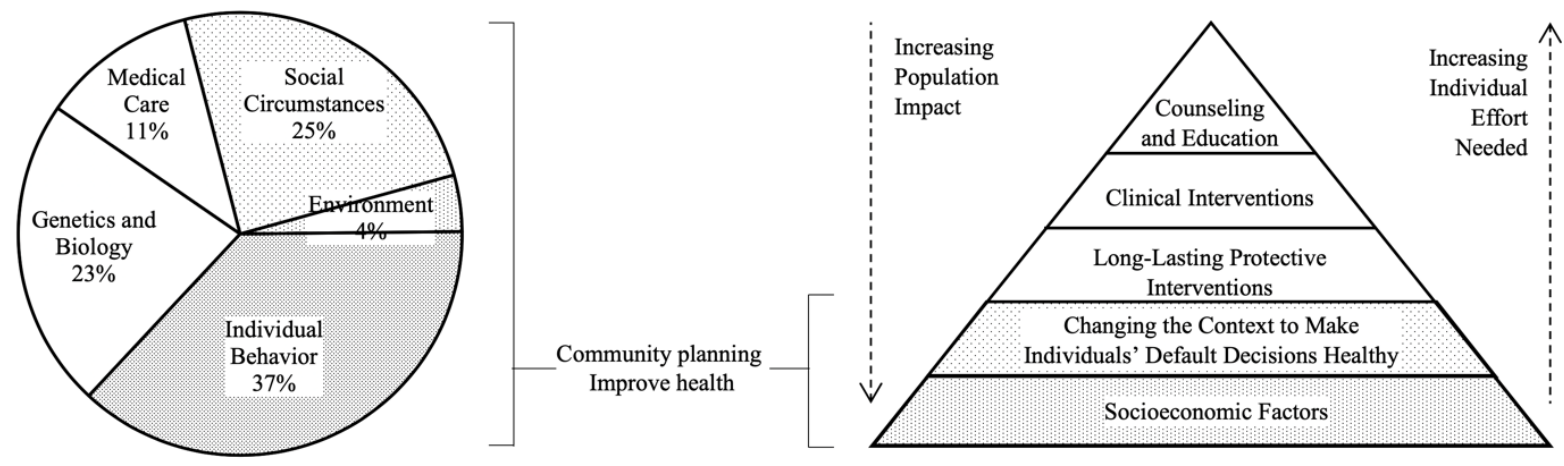

Figure 3. Proportion of Health Factors (left) and Health Impact Pyramid (right).

(2) The role of Community scale in disaster Prevention and reduction

The community has the characteristics of group organization in a certain space and is often regarded as the basic unit of disaster prevention and control. The main reasons are: 1) Community governance gives full play to the ability of self-organization from the bottom up, shortens the decision chain to deal with emergencies and the overall security. 2) Community spatial organization helps to build urban groups. through reasonable connection and blocking, it can not only form a distributed network that supports each other, but also be divided into relatively independent 'defense units'. 3) Community social connections play an important role in risk awareness, which in turn strongly affects the willingness to prepare for disasters. The community cohesion and residents' sense of responsibility cultivated at ordinary times will make a great contribution to the resilience of the community in the event of a disaster. 4) Community early warning monitoring plays a key role in opening the 'last one kilometer' of the emergency response network, which can alleviate the problems existing in the current information feedback system, such as poor accessibility, poor data quality, untimely reporting, staffing and insufficient funds. Therefore, strengthening community-based disaster preparedness management is essential to reduce deaths and losses caused by disasters. 


\subsection{Health potential of productive strategies}

According to different resource types, productive strategies can be divided into agriculture (food) and ecology, renewable energy, water, waste recycling, local manufacturing, culture and space (architecture, transportation, environment, etc.). Among them, community urban agriculture is a typical representative of green productive strategy. Urban agriculture has been regarded by many countries and regions as the root of the problem, or at most the survival choice of underdeveloped areas and residents. Before this form of open space is incorporated into urban construction and developed for other uses, it is mainly regarded as temporary land use, but its role in healthy urban planning is seriously underestimated. Because the most prominent feature of urban agriculture is not its geographical location, but that it is an integral part of urban health, social, economic ecology and governance system [23].

Although traditional agriculture has some health-related problems, such as contaminated irrigation water sources (industrial, medical and residential), animal and plant foodborne fungal viruses (plant mycotoxins, livestock farming and excreta), pesticide residues in crops or groundwater (fertilizers, insecticides and fungicides), drug-resistant pathogens, composting of food waste and occupational hazards in the food supply chain. However, with the development of urban ecological agriculture, most of the health risks can be avoided by selecting insect-resistant and antibacterial fruit and vegetable varieties, environmental protection cultivation substrate, professional guidance and standardized management and other measures.

The potential of urban agriculture to improve health in various ways has been gradually recognized and assessed in terms of social, economic, ecological and nutritional aspects, with the aim of maximizing health benefits and reducing negative impacts. 1) Social benefits are the most important, mainly in terms of quality of life, entrepreneurship and related skills, sharing and social networks, education and community programmes, and retail and support networks. 2) The economic benefits are mainly individual income, employment opportunities, economic development and food costs. High-tech food has the greatest commercial feasibility, but it may also increase the surrounding housing costs. 3) The ecological benefits are mainly greening to provide ecosystem services (regulation, supply, culture and support), agricultural horticulture activities can enhance physical exercise, relieve stress and improve immune capacity, while reducing environmental hazards, there are also agricultural health risks. 4) Nutritional benefits are the most direct, mainly reflected in local food consumption, fresh safety and healthy eating habits. (figure 4)
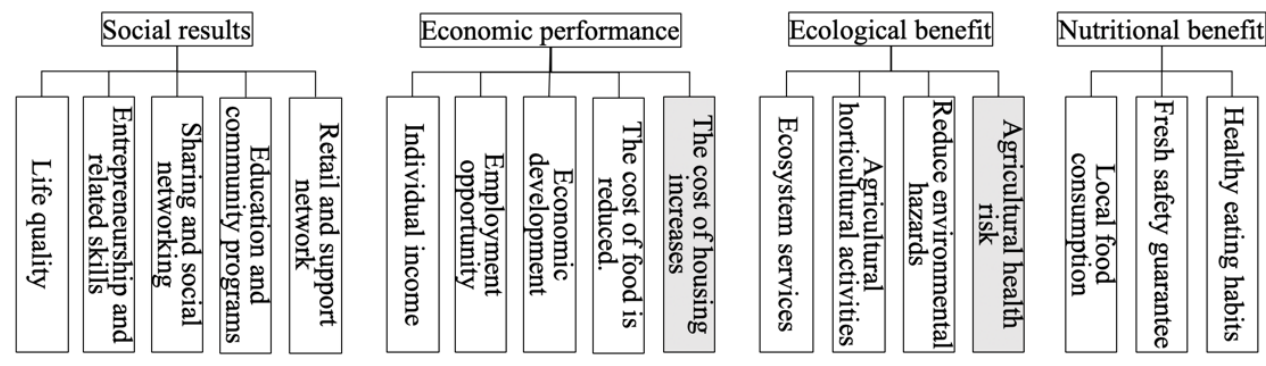

Positive influence

Negative influence

Figure 4. Health potential of urban agriculture.

\subsection{Case study on the practice of urban agriculture in community}

(1) Urban agriculture as a key area of community health planning practice

Program for Health supported by the American Planning Association (APA), the American Association of Public Health (APHA), and the CDC, is the first national community practice program in the United States to promote the cross-cutting areas of health and planning and to build sustainable cross-sectoral alliances through innovative partnerships. The project lasts for three years (2015-2018). Based on the specific 
strategies of 35 successful implementation cases in healthy communities in the first two years, it is found that the plan mainly works in two areas: 'slow transport system and local food system'. This has an impact on the two priority areas of health, 'access to food nutrition and promotion of physical exercise'.

Urban agriculture has both nutrition and exercise for healthy living, and should be regarded as the key area of community health planning practice. Observing the implementation cases and the distribution of vegetable production in the United States in 2017, areas with better food supply conditions have a higher acceptance of improved food systems in urban agriculture, which may be related to the healthy eating habits that have been developed (figure 5, left). Further observe the distribution of American community farmers' markets and the epidemic situation of COVID-19, considering the degree of population density, in most areas with convenient access to food, the number of confirmed cases is not serious (figure 5, right). Although urban agriculture needs further research on regional adaptability and epidemic mitigation, it does play a role in health protection in daily and emergency situations.
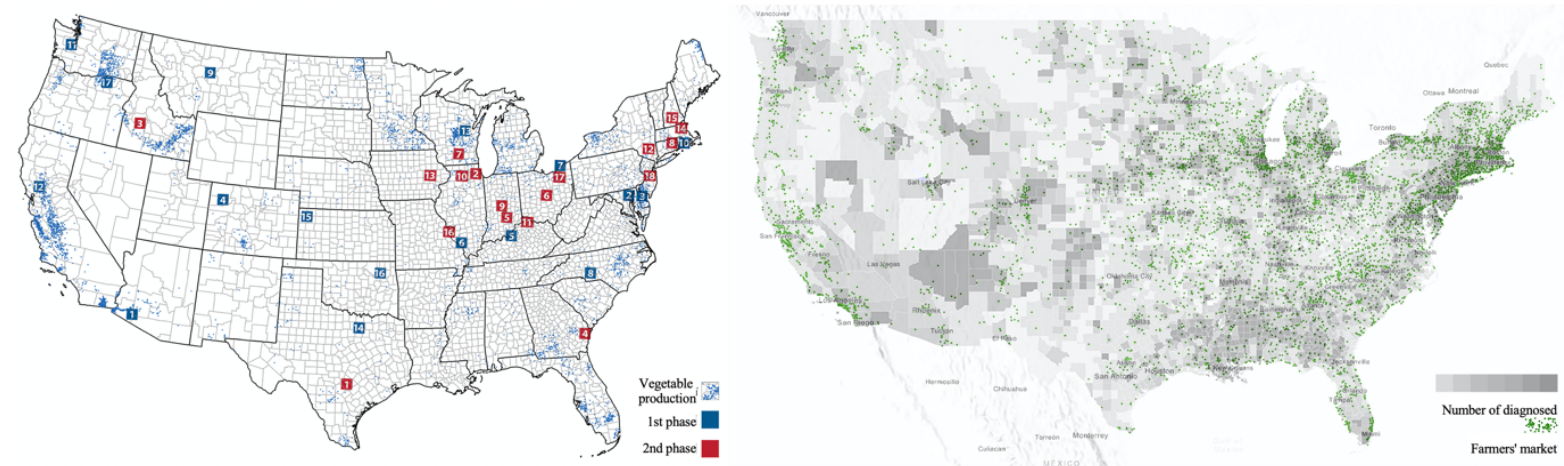

Figure 5. 35 healthy community cases and vegetable production map (left); community farmers' market and COVID-19 pandemic map (right).

(2) Daily slack health protection - Todmorden, West Yorkshire, UK

'Incredible Edible Todmorden, IET' is one of the most obvious and influential practices in the urban food movement. The project, known for growing community food in public places, is a comprehensive sustainable food program that aims to change the way people come into contact with food. The 'Incredible Edible Network (IE Network)' was established in 2012 and gradually expanded to about 1000 community groups around the world, demonstrating its potential for successful implementation in different environments. The 2017 summary report [24] assesses the social, economic and environmental impact of the edible model over the past decade, as well as its broader potential as a community-led framework. The research data confirmed the positive impact of change theory on the community, business and education sectors in the short, medium and long term, with a return on social investment of 1:5.51. In particular, the report mentions a number of information showing the role of IET in health and well-being. For example, during the 2012 and 2015 floods, residents provided food aid and restored community resilience through the community spirit fostered by IET. In addition, there is an increase in the level of exercise and improvement of physical and mental health, the establishment of a cooperative culture and friendly atmosphere, the enhancement of community cohesion, and the promotion of the sustainability and resilience of the food system and the local economy, all of which are determinants of healthy communities.

(3) Health protection for abnormal emergency - Nerima District, Tokyo, Japan

Global post-earthquake research reports show that the affected residents have dietary health problems. Due to the region's fragile food system and the unpredictability of the scale of disasters, emergency food has changed from short-term demand to long-term dependence, lack of fresh fruits and vegetables and carbohydrate-based diet lead to gastrointestinal symptoms and cardiovascular disease. According to the 
analysis of urban agricultural self-sufficiency in Tokyo's second most populous horse training area, the yield self-sufficiency rate of $6.18 \%$ and the nutrition self-sufficiency rate of $2.86 \%$ are much higher than $0.02 \%$ during the 2011 earthquake in northeastern Japan [25]. This is related to the fact that the local government actively promotes and subsidizes urban agricultural activities. Community farmers create experience farms to improve the self-sufficiency of the area, and their further democratization achieves overall popularization in the areas of education and leisure. In addition, the government of the training area organized community urban agricultural participants to conduct disaster drills as an additional disaster preparedness measure. The comprehensive evaluation of its pre-disaster investment shows that urban agriculture can be used as a source of food in the affected areas and play a further role in the process of long-term recovery. From the food security and nutrition source of residents to the positive impact on mental health and community resilience.

\section{Health planning strategy of green productive community}

\subsection{Community health planning with systematic thinking}

In 2020, some measures on the community scale have played a great role in controlling the epidemic situation of COVID-19, but at the same time, some problems have been exposed, such as lack of facilities, tight space, weak organization, management contradictions and so on. it reflects that the function of community space in our country still needs to be improved. In fact, the root cause of the current improper allocation of resources, monotonous spatial vitality, alienation of neighborhood relations and single functional zoning lies in the lack of the perspective of 'community spatial function system'.

Community is not only a level of urban giant system, but also a complex system, in which material flow, energy flow, information flow and personnel flow are constantly exchanged. Therefore, the community should not only undertake the ecological, social, economic, service and innovation functions in part of the urban system, but also have system attributes. Using systematic thinking to understand the relationship between community functions, design modifications and expected results, which is conducive to the system to work together to increase independent functions, and even stimulate new functions at the system level. The health planning strategy of the green productive community is to take the productive function as the 'catalyst', optimize the community space and enhance the system function in parallel, so as to increase the sustainability of the daily state and the flexibility of the abnormal state.

\subsection{Functional implantation increases the flexibility of the system to cope with abnormal}

states

When the world is in crisis and facing the unpredictability and uncertainty of disasters, planners and policy makers try to deal with current problems through the concept of flexibility. 'productive function implantation' can effectively improve the resilience of the system. Taking community urban agriculture as an example, four areas are improved by the three steps of 'spatial screening - strategy application - effect evaluation': 1) Ecological elasticity. Such as the use of backyard, balcony of the family farm, reduce food mileage to reduce carbon emissions. 2) Economic flexibility. Such as choosing low-cost outdoor modular planting box or high-cost indoor soilless cultivation technology to shorten the distance between production and consumption, shorten the supply chain and increase feedback sensitivity. 3) Social flexibility. Such as the transformation of open land to build community agricultural gardens, enrich the diversity of food sources, meet the short-term partial self-sufficiency, and achieve relative independence. 4) Engineering flexibility. Such as building a roof greenhouse to help buildings waterproof and heat preservation, laying porous roads and infiltration ditches, Rain Water recycling and enhance the 
durability of infrastructure. On the whole, urban agriculture enhances the diversity, moderate redundancy and adaptive integration of the community food system.

\subsection{Functional reorganization increases sustainability in the face of daily state}

The system not only needs to deal with emergency shocks, but also needs to face daily stress. At present, the community functions that should be cultivated and improved in our country mainly include management, service, security, education, security and stability. The ecosystem service function has been added after the urban agricultural function is implanted, which creatively fills the original only social service function. The new functions should be 'reorganized' with existing functions to form four new services and further enhance the sustainability of the system. 1) Provide services. Combine the community retail direct selling formats such as mobile stalls, corner shops and farmers' bazaars to provide local fresh and healthy food supply. 2) Regulating service. Productive greening not only manages the environment in terms of mitigating temperature, improving air, purifying runoff and buffering noise, but also promotes neighborhood interaction and cohesion to strengthen community management. 3) Cultural service. School gardens provide additional opportunities for students to participate in work, harvest and sharing, helping to cultivate a good food culture; community gardens and therapeutic gardens play an important role in recreation and mental health of residents. 4) Support services. Postprandial kitchen waste compost can be used as planting substrate to maintain resource circulation, fruit and vegetable variety matching and seasonal rotation can protect biodiversity, and high roof agriculture, patchy distribution gardens and chain fruit tree corridors form a continuous productive environment. Provide habitat for pollination media. (figure 6)
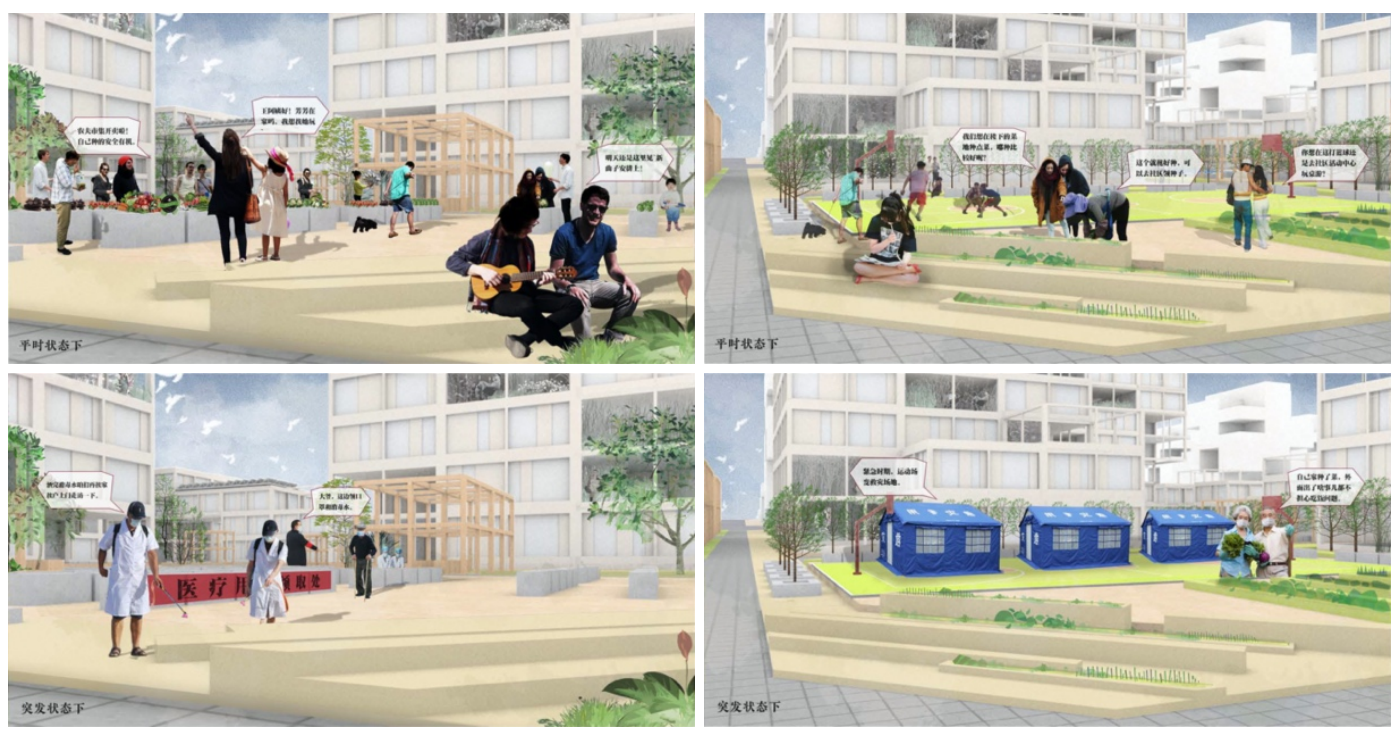

Figure 6. Community urban agriculture in daily state (top) and abnormal state (bottom).

\subsection{The role of health planning in the complete integration of productive systems}

Urban agriculture in green productive communities is a food cycle system covering production, harvest, transportation, retail, consumption and treatment, and the relationship between productive strategies of different resource types is also a system. According to the mapping relationship between two systems, the food system can be used as the comprehensive result of the productive system. (figure 8)

On the basis of the implantation and reorganization of productive functions, the integration of productive systems into urban health planning can play five major roles: food security function, eco-environmental function, leisure and cultural function, technological demonstration function and commercial and social security function. (table 1) with the help of the complete food system cycle, the complex relationship 
between urban agriculture's health-related functions and their direct or indirect effects on health are conceptualized around the planning of social, spatial and behavioural factors that affect health. (figure 9)

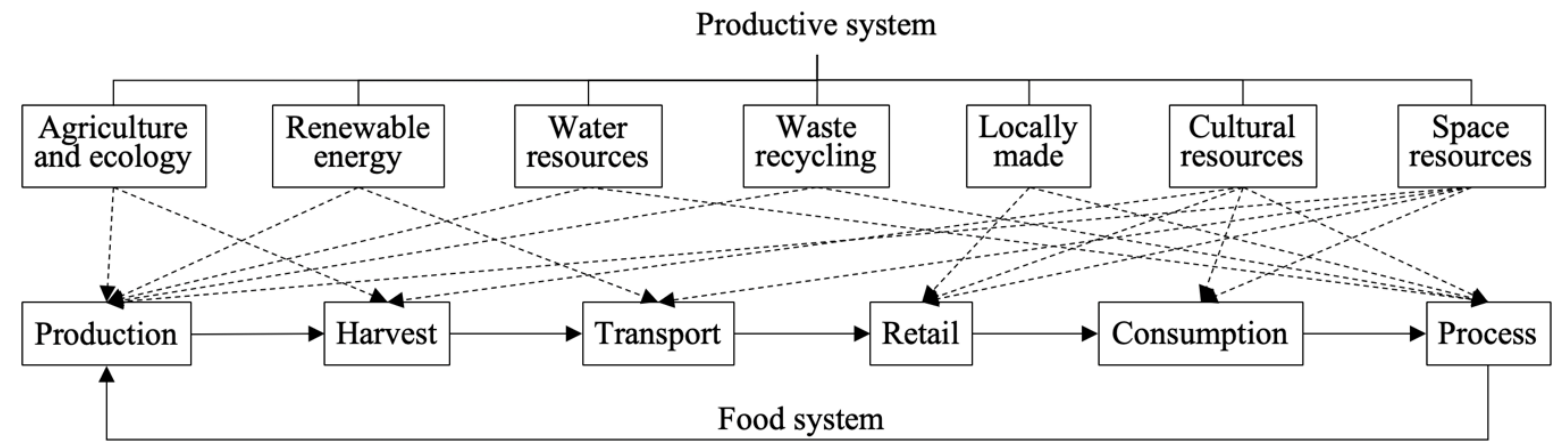

Figure 7. The relationship between productive system and food system.

\begin{tabular}{|c|c|c|}
\hline \multicolumn{2}{|c|}{ Function } & Specific content \\
\hline Food security & $\begin{array}{c}\text { safe food } \\
\text { system }\end{array}$ & $\begin{array}{l}\text { local food production; shorten the supply chain; alternative supply } \\
\text { network; short-term or partial self-sufficiency; }\end{array}$ \\
\hline \multirow[b]{2}{*}{$\begin{array}{l}\text { Ecological } \\
\text { environment }\end{array}$} & $\begin{array}{l}\text { greening } \\
\text { environment }\end{array}$ & $\begin{array}{l}\text { landscape aesthetics; filter air particles and reduce noise; alleviate heat } \\
\text { island effect }\end{array}$ \\
\hline & $3 \begin{array}{c}\text { Ecological } \\
\text { sustainability }\end{array}$ & $\begin{array}{l}\text { responding to climate change; reducing carbon emissions (vegetating } \\
\text { carbon sequestration, reducing food mileage); green infrastructure; } \\
\text { reducing rainwater runoff (preventing toxic waste from entering natural } \\
\text { water systems); biodiversity; agricultural diversity; healthy ecosystems }\end{array}$ \\
\hline \multirow{3}{*}{ Leisure culture } & $\begin{array}{l}\text { Improving } \\
\text { mental health }\end{array}$ & $\begin{array}{l}\text { short-term psychological relief; long-term mental health care; therapeutic } \\
\text { landscape }\end{array}$ \\
\hline & $\begin{array}{l}\text { Improve } \\
\text { exercise level }\end{array}$ & agricultural work \\
\hline & $6 \begin{array}{c}\text { Adjust living } \\
\text { habits }\end{array}$ & $\begin{array}{l}\text { guide consumption trends; eating habits (reduce the intake of deeply } \\
\text { processed foods that cause obesity or malnutrition) }\end{array}$ \\
\hline $\begin{array}{c}\text { Technical } \\
\text { demonstration }\end{array}$ & $\begin{array}{l}\text { Innovative } \\
\text { technology }\end{array}$ & $\begin{array}{l}\text { respond to the challenges of resources, energy, waste and space; provide } \\
\text { fresh and healthy food; brownfield restoration }\end{array}$ \\
\hline \multirow{5}{*}{$\begin{array}{l}\text { Commercial } \\
\text { and social } \\
\text { security }\end{array}$} & $\begin{array}{c}\text { Inequality } \\
\text { issues }\end{array}$ & $\begin{array}{l}\text { empower local groups with spatial rights; food justice for low-income } \\
\text { groups; distributed food system }\end{array}$ \\
\hline & $9 \begin{array}{c}\text { Community } \\
\text { cohesion }\end{array}$ & $\begin{array}{l}\text { producer-consumer democratic cooperation; community organization } \\
\text { contact; stress relief; emergency response capability; aftershock society }\end{array}$ \\
\hline & $\begin{array}{l}\text { Employment } \\
\text { and services }\end{array}$ & $\begin{array}{l}\text { small businesses stimulate the community economy; new business } \\
\text { models }\end{array}$ \\
\hline & 11 Education & sustainable agriculture education; healthy food culture \\
\hline & $12 \begin{array}{c}\text { Economic } \\
\text { growth }\end{array}$ & $\begin{array}{l}\text { close to consumers; distribution network closely linked to the market; } \\
\text { fight against cheap imports; aftershock economy }\end{array}$ \\
\hline
\end{tabular}

Table 1. Related functions of urban agriculture that contribute to health. 


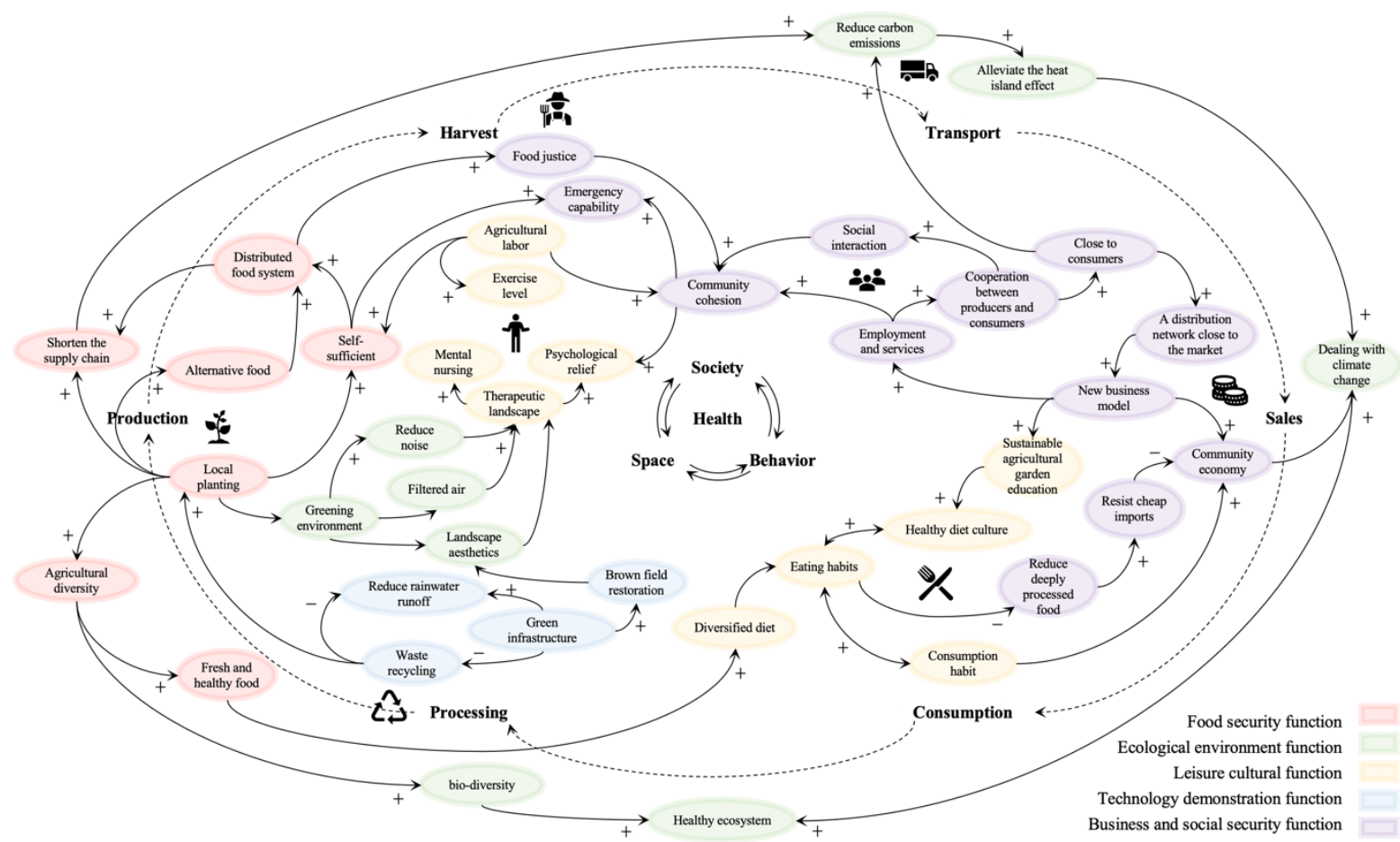

Figure 8. The relationship between the functions of urban agriculture and its effect on community health.

\section{References}

[1] WHO.(2019) Health Emergency and Disaster Risk Management Framework [online]. Available at: https://www.who.int/activities/implementing-emergency-and-disaster-risk-management (Accessed: 24 May 2020)

[2] Zhao, J. (2020) 'Pestilence, Urban Public Health and Landscape Architecture: Impacts of Two Severe Infectious Diseases on Urban Public Health and Landscape Architecture in British History', Landscape Architecture, 27(04), 101-105.

[3] Ahmed, M.Z., Ahmed, O., Aibao, Z., et al. (2020) 'Epidemic of COVID-19 in China and associated Psychological Problems', Asian Journal of Psychiatry, 51 [online]. Available at: doi:10.1016/j.ajp.2020.102092

[4] Aubry, C., Duchemin, E., Nasr, J. (2017) Urban Agriculture [online]. Available at: http://www.springer.com/series/11815 (Accessed: 24 May 2020)

[5] Gottero, E. (2019) Agrourbanism [online]. Available at: http://www.springer.com/series/6007 (Accessed: 24 May 2020)

[6] Sun, Y.B. (2013) Urban Agriculture and Its Potential in Urban Development, Tianjin: Tianjin University.

[7] Li, J. (2013) 'Modern Urban Agricultural Landscape Infrastructure', Landscape Architecture, (03), $20-23$.

[8] Li, X., Zhang, Y.L., Mu, H.K., et al. (2020) 'Vision and Mission: Landscape Architecture in Response to Public Health', Landscape Architecture, 27(04), 91-94.

[9] Alaimo, K., Beavers, A.W., Crawford, C., et al. (2016) 'Amplifying Health Through Community Gardens: A Framework for Advancing Multicomponent, Behaviorally Based Neighborhood Interventions'. Current Environmental Health Reports, 3(3), 302-312. 
[10] Canadian Institute of Planners. (2014) Healthy Communities Practice Guide [online]. Available at: http://cip-icu.ca/Healthy-Communities (Accessed: 24 May 2020)

[11] Ricklin, A., Shah, S. (2017) Metrics for Planning Healthy Communities [online]. Available at: https://planning.org/publications/document/9127204/ (Accessed: 24 May 2020)

[12] City of Melbourne. (2019) Council Plan 2017-2021 (2019 Update) [online]. Available at: https://www.melbourne.vic.gov.au/sitecollectiondocuments/council-plan-2017-21.pdf (Accessed: 24 May 2020)

[13] United Nation. (2019) World urbanization prospects: the 2018 revision [online]. Available at: https://population.un.org/wup/Publications/ (Accessed: 24 May 2020)

[14] Lee, V.J., Ho, M., Chen, W.K., et al. (2020) 'Epidemic preparedness in urban settings: new challenges and opportunities', The Lancet Infectious Diseases, 20(5), 527-529.

[15] Yang, J., Siri, J.G., Remais, J.V., et al. (2018) 'The Tsinghua-Lancet Commission on Healthy Cities in China: unlocking the power of cities for a healthy China', Lancet, (391)10135,2140-2184.

[16] Yang, J.Y., Shi, B.X. and Shi, Y. (2020) 'Construction of a Multi-scale Spatial Epidemic Prevention System in High-density Cities', City Planning Review, 44(03), 17-24.

[17] Byrne, J.A., Houston, D. (2020) 'Urban Ecology' in Kobayashi, A. (ed.) International Encyclopedia of Human Geography (Second Edition). Amsterdam: Elsevier, 14, 47-58.

[18] Imperiale, A.J., Vanclay, F. (2016) 'Experiencing local community resilience in action: Learning from post-disaster communities' Journal of Rural Studies, 47, 204-219.

[19] Zhang, Y.K., Zheng, J. (2016) 'A Call for New Spirit A Centurial Turn of the Contemporary Cities and Buildings', Architectural Journal, (10), 114-119.

[20] Schroeder, S.A. (2007) 'We Can Do Better-Improving the Health of the American People', New England Journal of Medicine, 357(12), 1221-1228.

[21] Frieden, T.R. (2010) 'A Framework for Public Health Action: The Health Impact Pyramid', American Journal Public Health, 100(4), 590-595.

[22] Center for Disease Control and Prevention. (2018) Health Impact in 5 Years [online]. Available at: https://www.cdc.gov/policy/hst/hi5/index.html (Accessed: 24 May 2020)

[23] Mougeot, L.J.A. (2000) Urban agriculture: definition, presence, potentials and risks, and policy challenges. Growing Cities, Growing Food: Urban Agriculture on the Policy Agenda [online]. Available at: https://idl-bncidrc.dspacedirect.org/bitstream/handle/10625/26429/117785.pdf?sequence=12 Accessed: 24 May 2020)

[24] Farrier, A., Dooris, M., Morley, M. (2019) 'Catalysing change? A critical exploration of the impacts of a community food initiative on people, place and prosperity', Landscape and Urban Planning, 192. [online]. Available at: doi:10.1016/j.landurbplan.2019.103663

[25] Sioen, G.B., Sekiyama, M., Terada, T., et al. (2017) 'Post-Disaster Food and Nutrition from Urban Agriculture: A Self-Sufficiency Analysis of Nerima Ward, Tokyo', Int. J. Environ. Res. Public Health, 14(7), 748. 